\title{
Effect of a Community-Led Total Sanitation Intervention on Sanitation and Hygiene in Pallisa District, Uganda
}

\author{
Charles Dickens Okolimong, ${ }^{1,2 *}$ Rawlance Ndejjo, ${ }^{1}$ Richard K. Mugambe, ${ }^{1}$ and Abdullah Ali Halage ${ }^{1}$ \\ ${ }^{1}$ Department of Disease Control and Environmental Health, School of Public Health, College of Health Sciences, Makerere University, Kampala, \\ Uganda; ${ }^{2}$ Pallisa District Local Government, Pallisa, Uganda
}

\begin{abstract}
We conducted a comparative cross-sectional study to examine the potential effects of a community-led total sanitation (CLTS) intervention on sanitation and hygiene in Pallisa district in Uganda. Quantitative data were collected from households using a semi-structured questionnaire and an observation checklist, entered and analyzed using univariate, bivariate, and multivariate analyses. Overall, knowledge on sanitation and hygiene was significantly higher $(64.5 \% ; 129 / 200)$ among households in the CLTS intervention than among those in the nonintervention subcounties $(54.0 \% ; 108 / 200)(P=0.033)$. Latrine quality was rated as fair in a majority $(73.3 \% ; 143 / 195)$ of the CLTS intervention households compared with $50.8 \%(93 / 183)$ in the non-CLTS households $(P<0.001)$. Latrine cleanliness was rated as good in more than a half $(51.3 \% ; 100 / 195)$ of households in the intervention area, whereas only $13.7 \%(25 / 183)$ for the nonintervention area $(P<0.001)$. In this study, 35.0\% $(70 / 200)$ of the households in the intervention subcounty had attained open defecation-free (ODF) status compared with only $6.0 \%(12 / 200)$ in the nonintervention subcounty $(P<$ 0.001 ). Level of knowledge on hygiene and sanitation (adjusted odd ratio [AOR]: $2.23 ; 95 \% \mathrm{Cl}: 1.24-4.03$ ) and CLTS status (AOR: 8.89; 95\% Cl: 4.26-18.56) were significantly associated with achievement of ODF status in the multivariate analysis. The mean cases of diarrhea were significantly lower in CLTS implementing (subcounty $(0.42$ [SD \pm 1.03 ]) than in the nonCLTS implementing subcounty $(0.98[S D \pm 1.39] ; t=-4.6 ; P<0.001)$. Sanitation and hygiene outcomes were better in the CLTS intervention subcounty than in the non-CLTS intervention subcounty, suggesting that scaling up CLTS could reduce ODF and the burden of diarrheal diseases.
\end{abstract}

\section{INTRODUCTION}

Globally, 2.0 billion people lack improved sanitation and 946 million practice open defecation (OD). ${ }^{1}$ Between 2000 and 2017 , the net reduction in the global population practicing open defecation decreased by 647 millions. ${ }^{1}$ However, there were disparities in the reductions with countries in Central and South Asia recording the largest reduction of 496 million, whereas sub-Saharan Africa reduced open defecation by 5 million people. ${ }^{1}$ A report released by the WHO in 2012 indicated that about 1.5 million children younger than 5 years die each year from sanitation-related diseases such as diarrhea, which could be prevented by community-led total sanitation (CLTS). ${ }^{2}$ Uganda was not able to meet its 2015 millennium development goal of increasing sanitation and hygiene coverage to $75 \% .^{3}$ The country has generally experienced stagnation in progress in achieving better sanitation and hygiene ${ }^{4}$ with $18 \%$ of the population without access to at least basic sanitation, $18 \%$ had limited (shared) sanitation, and $58 \%$ had unimproved sanitation in $2017 .^{1}$ Moreover, $6 \%$ of the population was estimated to still be practising OD by $2017 .{ }^{1}$

The Uganda Ministry of Health with support from Global Sanitation Fund recognized and implemented the CLTS approach in selected districts including Pallisa. The approach is considered an effective and low-cost mechanism to promote better sanitation and hygiene at the household level. The focus of CLTS is to trigger the community to generate sustained behavioral change leading to spontaneous and long-term abandonment of open defecation practices and to stimulate demand for safe sanitation and hygiene facilities without provision of any facilities or subsidies. ${ }^{5}$ Indeed, in Pakistan, effective CLTS implementation resulted in improved latrine

*Address correspondence to Charles Dickens Okolimong, Pallisa District Local Government, P.O. Box 14, Pallisa, Uganda. E-mail: c.okolimong@yahoo.com coverage in all the target districts, which reduced open defecation practices in the communities. ${ }^{6}$ In rural Zambia, CLTS activities elicited strong emotions, including shame, disgust, and peer pressure, which persuaded individuals and families to build and use latrines and hand-washing facilities. ${ }^{7}$ Previous findings have also indicated that the prevalence of childhood diarrhea was significantly higher in communities where CLTS was not implemented than in the intervention areas. ${ }^{8,9}$

The implementation of the CLTS intervention in Uganda was expected to achieve $100 \%$ open defecation-free (ODF) status, better sanitation and hygiene status (latrine and hand-washing coverage, latrine quality, and cleanliness), reduced prevalence of diarrheal diseases, and communities with adequate knowledge on sanitation and hygiene in selected districts. In Pallisa district, although CLTS had been implemented for 7 years, its outcomes/effects had not been evaluated. This study therefore examined the potential effects of the CLTS intervention in Pallisa district by comparing CLTS implementing and non-implementing subcounties.

\section{METHODS}

Study area and population. This comparative crosssectional study was conducted in two subcounties in Pallisa district in Eastern Uganda located 196 km from Kampala city, Uganda's capital. The district consists of 52 parishes, 301 villages, and 46,170 households with a population of 275,600 people ${ }^{10}$ and is largely rural, with only $11.8 \%$ of the population living in urban areas. The main economic activities in Pallisa district include small-scale agriculture, fishing, and trade. The top five diseases registered in the district include malaria, diarrhea, acute respiratory diseases, intestinal worms, and skin diseases in that order. ${ }^{11}$ The study population were residents in Apopong (CLTS intervention) and Puti-Puti (non-CLTS intervention) subcounties, and respondents were adult 
household members aged 18 years and older. Apopong subcounty was purposively selected because this is where the CLTS approach was piloted by the Ministry of Health and is also the concentration subcounty with CLTS being implemented in all parishes unlike other subcounties. Among the non-CLTS subcounties, Puti-Puti was purposively selected because it is similar in context (demographics, and rural and economic activities) and was the furthest from Apopong subcounty approximately $24 \mathrm{~km}$ apart and therefore limited chances of exposure to CLTS intervention. A total of 400 households (200 from each subcounty) were visited and a corresponding number of respondents interviewed.

The intervention. The CLTS intervention was implemented in Apopong subcounty starting in 2011 and involved pretriggering, triggering, monitoring, and declaration of ODF status. During pre-triggering, local leaders, community health workers, and other opinion leaders were mobilized and briefed about the intervention (objectives, procedure, and benefits) by the health assistant and the environmental health staff in charge of a subcounty, sometimes supported by a health educator, both of whom had undergone CLTS training by the ministry of health staff. Triggering was mainly performed through transect walks which involved walking with community members through the village while observing sanitation and hygiene practices, asking related questions, and listening. During the transect walk, CLTS facilitators and community members were able to identify and visualize areas of OD and visit the different types of latrines to establish characteristics of good and safe sanitation and hygiene facilities. Interested community members (first responders) were identified, and demonstrations were made of acceptable sanitation facilities made of local materials including tippy taps by community engineers/masons. A tippy tap is a simple device for handwashing with a container that holds water, which is tipped by a foot-operated stick and rope tied through a small hole in the container cap for water to flow during handwashing. The CLTS implementation was monitored by the community sanitation committee (CSC) with the support of the health assistant. After about 4-6 months of implementation, an ODF claim (initiated by the chairperson CSC) was submitted to the health assistant. A follow-up was performed by a subcounty team (the health assistant, health educator, and the community health worker) to verify and declare the village ODF status using the predefined parameters. Implementation started with a few villages and expanded until the whole subcounty was covered. During the intervention, community education was performed through a radio talk show twice every year although efforts of community health workers in educating community members continued during the implementation. In the control community (Puti-Puti subcounty), usual activities continued, which included periodic visits from health assistants and community health workers to address general health issues including sanitation and hygiene. Some nongovernmental organizations also implemented sanitation- and hygienerelated activities majorly in schools and health facilities within the district.

Sample size and sampling. Sample size was calculated using the formula for two population proportion comparative studies with categorical outcomes. ${ }^{12}$ The proportion of households practicing open defecation was considered because CLTS focuses mainly on eliminating open defecation practices. The calculated sample size was 200 households from each subcounty. The study participants were selected by a multistage sampling procedure. From the selected subcounties, three parishes were randomly selected from each, and three villages were randomly selected from the parishes. Systematic random sampling was then used to select households from the villages. The number of households selected from each village was based on the total number of households therein through the probability proportionate to size sampling which also determined the sampling interval. The first household was selected while at the center of the village guided by the compass direction. Where respondents were not found home, the nearest household was interviewed.

Data collection. Quantitative data on sociodemographic factors and knowledge about sanitation and hygiene were collected using a semi-structured questionnaire, whereas observational checklists were used to collect data on ODF latrine and handwashing status. The data collection instruments (Supplemental Information) were adapted from the previous literature on sanitation ${ }^{13}$ and pretested in a similar community and necessary adjustments made. Data were collected by a team of research assistants who underwent a 2-day training on the study aspects before being deployed. At least one eligible respondent, who was an adult member in their households, was identified and interviewed. Where more than one adult was present in a selected household, preference was given to the household head, their spouse, or the next adult member. Data collection took place in May 2018.

Definition of variables. The primary outcome variable was the proportion of households that had achieved ODF status, and this was determined based on the following four CLTS standards/indicators ${ }^{13}$ assessed using an observational checklist.

1. Absence of feces in the vicinity of the household

2. A latrine with a superstructure with a means of keeping flies from the pit (either water seal or lid)

3. Handwashing facilities with water and soap or soap substitute such as ash

4. Evidence that the latrine and handwashing facilities were being used (e.g., a well-trodden path)

Binary outcome was used based on whether the households had achieved the ODF status or not, with those that had met all the four CLTS standards/ODF indicators described as having achieved ODF status and the rest categorized otherwise. The other secondary outcome variables were as follows.

1. Latrine status defined by the availability of latrines, presence of latrines with covers, presence of latrines with covers that are tight fitting, and evidence of use of latrines (fresh feces in a pit, recent flushing for pour flush latrines, and worn track to latrine from the house).

2. Latrine quality which was described as follows.

a. Good quality where the roof, walls, and floor were made of permanent materials; the floor was washable; complete latrine structure; the pit was lined with permanent materials; and the latrine had door to provide privacy for the user;

b. Fair quality. The roof, walls, and floor were made of semipermanent materials; the floor was not washable; the latrine had complete structure; the pit was either or not lined with permanent materials; and the latrine had a door/temporary shutter to provide privacy for the user; 
c. Poor quality where the latrine roof, walls, and floor were made of temporary materials; the floor was made of mud and washable; the latrine had no superstructure; and the pit was not lined and lacked door/temporary shutter to provide privacy for the user.

3. Latrine cleanliness described as good, that is, no sign of excreta (feces and urine) anywhere. Clean and tidy, fair, that is, excreta (feces and urine) around squat hole/squatting plate only; and poor, that is, feces and urine on floor, walls, etc.

4. Handwashing/facility status was based on the presence of handwashing facilities; presence of handwashing facilities with only water; presence of handwashing facilities with water, soap, or soap substitute, for example, ash; and evidence of use of handwashing facilities (wetness on ground below handwashing facility, worn track, and other signs of recent use).

5. Knowledge regarding sanitation and hygiene which was determined based on the ability of the respondents to correctly identify critical times for handwashing, benefits of using a latrine and handwashing facilities, causes of diarrhea, and prevention of diarrhea. Respondents who mentioned at least four critical times of handwashing, at least four benefits of latrine use and handwashing facilities, at least four causes of diarrhea, and at least three ways of preventing diarrhea were regarded as knowledgeable and the rest classified otherwise.

6. Prevalence of diarrhea was determined based on a child younger than 5 years who experienced diarrhea in the past 2 weeks preceding the study. ${ }^{14}$ The independent (explanatory) variables were sociodemographic variables.

Data management and analysis. The collected data were coded and entered into EpiData version 3.02 (EpiData Association, Odense, Denmark). The data were then exported to STATA 13 (StateCorp., College Station, TX) for cleaning and analysis. Descriptive statistics including frequencies and proportions for categorical variables and means and SDs for continuous variables were used to describe the study subjects at the univariate level. Chi-square $\left(x^{2}\right)$ test was used to compare the proportions between subcounties to establish whether they were statistically different based on $P$-value less than 0.05 . Odds ratios were obtained to measure the associations, whereas $P$-values $(P<0.05)$ at $95 \% \mathrm{Cl}$ were used to test for any associations at bivariate and multivariate analyses-which controlled for potential confounders. Two-sample $t$-test with unequal variances was used to compare means of diarrhea cases between CLTS and non-CLTS intervention subcounties.

Ethics approval and consent to participate. The Makerere University School of Public Health Higher Degrees and Ethics Committee provided ethical clearance for the study, and the Uganda National Council for Science and Technology registered it. All study participants provided written informed consent, and confidentiality and privacy were upheld.

\section{RESULTS}

Sociodemographic characteristics of the respondents. A total of 400 households participated in the study, of which half were from Apopong subcounty (CLTS intervention area) and the rest were from Puti-Puti subcounty, the nonintervention area. Respondents in the CLTS and non-CLTS intervention communities were statistically different as regards their age, gender, tribe, monthly income, marital status, education level, religion, and duration lived in the village $(P<0.05)$. The mean age of respondents was $43.4(S D \pm 15)$ years in the CLTS intervention subcounty and $54.7(S D \pm 18.5)$ years in the nonCLTS intervention area. Among respondents, 93.0\% (186/200) and $79.0 \%(158 / 200)$ had lived in the CLTS and non-CLTS intervention areas, respectively, for over 3 years (Table 1).

Knowledge on sanitation and hygiene among households in the two communities. Table 2 shows that a majority $(91.0 \% ; 182 / 200)$ of respondents in the CLTS intervention area and the nonintervention $(86.0 \% ; 172 / 200)$ area mentioned handwashing before eating food as one of the critical times. In addition, a high proportion $(78.5 \% ; 157 / 200)$ of respondents in the intervention area and half (50.0\%; 100/200), in the nonintervention area mentioned dirty hands as causes of diarrhea. However, overall knowledge levels were higher (64.5\%; 129/200) among households in the CLTS implementing area than among those in the non-CLTS-implementing subcounty $(54.0 \% ; 108 / 200)$, and the difference was statistically significant $(P=0.033)$ (Table 2$)$.

Latrine and handwashing status among households in the two subcounties. Latrine coverage stood at 97.5\% (195/ $200)$ in the CLTS intervention areas and $91.5 \%(183 / 200)$ in the nonintervention areas, and the difference in proportions was not statistically significant $(P=0.100)$. Moreover, a high proportion $(97.4 \% ; 190 / 195)$ of households in the CLTS and the non-CLTS $(96.7 \% ; 177 / 183)$ subcounties had traditional pit latrines. Latrine quality was rated as fair in a majority $(73.3 \%$; 143/195) of households in CLTS compared with 50.8\% (93/ 183) for non-CLTS households. Latrine cleanliness was rated as good in more than a half $(51.3 \% ; 100 / 195)$ of households in the intervention area compared with only $13.7 \%$ (25/183) for the nonintervention area. The difference in proportions of both latrine quality and cleanliness between households in the two study areas was statistically significant $(P<0.001)$ (Table 3).

Open defecation-free (ODF) indicators and status between households in CLTS intervention and nonintervention subcounties. The overall results showed that $35.0 \%$ (70/200) of the households in the intervention area had attained ODF status compared with only $6.0 \%$ (12/200) for nonintervention subcounty, and the difference was statistically significant $(P<0.001)$. It was further observed that households in CLTS and non-CLTS intervention communities were statistically different with respect to having latrines with tight-fitting squat-hole covers, handwashing facilities with water and soap, and evidence of latrine and handwashing facility use $(P<0.001)$ (Table 4$)$.

Factors associated with ODF status in two subcounties. Table 5 shows the crude and adjusted odds ratios for the factors associated with ODF status. Factors associated with attainment of ODF status were CLTS implementation status (crude odds ratio [COR]: 8.44; 95\% Cl: 4.40-16.19), knowledge on sanitation and hygiene (COR: 2.34; $95 \% \mathrm{Cl}$ : 1.36-4.03), and respondent having had post-primary education (COR: 1.97; 95\% Cl: 1.11-3.49). At multivariate analysis, the predictors for attainment of ODF status were CLTS status (AOR: 8.89; 95\% Cl: 4.26-18.56; $P<0.001$ ) and level of knowledge on sanitation and hygiene (AOR: 2.23 ; $95 \% \mathrm{Cl}$ : 1.24-4.03; $P=0.008)$.

Prevalence of diarrhea in children younger than 5 years among households in the two subcounties. The mean number of diarrhea cases in CLTS intervention subcounty was $0.42(S D \pm 1.03)$ and $0.98(S D \pm 1.39)$ cases in the non-CLTS subcounty. Two-sample $t$-test revealed that the mean cases 
TABLE 1

Sociodemographic characteristics of the respondents

\begin{tabular}{|c|c|c|c|c|}
\hline Variable & $\begin{array}{l}\text { CLTS intervention areas } \\
(N=200), n(\%)\end{array}$ & $\begin{array}{c}\text { Non-CLTS intervention areas } \\
(N=200), n(\%)\end{array}$ & $x^{2}$ & $P$-value \\
\hline \multicolumn{5}{|l|}{ Age (years) } \\
\hline $18-25$ & $15(7.5)$ & $9(4.5)$ & \multirow{5}{*}{40.92} & \multirow[t]{5}{*}{$<0.001$} \\
\hline $26-35$ & $57(28.5)$ & 27 (13.5) & & \\
\hline $36-45$ & $50(25.0)$ & $36(18.0)$ & & \\
\hline $46-55$ & $40(20.0)$ & $30(15.0)$ & & \\
\hline 56 and older & $38(19.0)$ & $98(49.0)$ & & \\
\hline \multicolumn{5}{|l|}{ Tribe } \\
\hline Mugwere & $17(8.5)$ & $91(45.5)$ & \multirow[t]{3}{*}{90.70} & \multirow[t]{3}{*}{$<0.001$} \\
\hline Itesot & $171(85.5)$ & $84(42.0)$ & & \\
\hline Others & $12(6.0)$ & $25(12.5)$ & & \\
\hline \multicolumn{5}{|c|}{ Duration lived in the village (years) } \\
\hline 3 years and less & $14(7.0)$ & $42(21.0)$ & \multirow[t]{2}{*}{35.20} & \multirow[t]{2}{*}{$<0.001$} \\
\hline More than 3 years & $186(93.0)$ & 158 (79.0) & & \\
\hline \multicolumn{5}{|l|}{ Gender } \\
\hline Male & $185(92.5)$ & $141(70.5)$ & \multirow{2}{*}{32.1} & \multirow{2}{*}{$<0.001$} \\
\hline Female & $15(7.5)$ & $59(29.5)$ & & \\
\hline \multicolumn{5}{|l|}{ Marital status } \\
\hline Married & $19(95.5)$ & $166(83.0)$ & \multirow[t]{2}{*}{16.3} & \multirow[t]{2}{*}{0.001} \\
\hline Not married & $9(4.5)$ & $34(17.0)$ & & \\
\hline \multicolumn{5}{|l|}{ Religion } \\
\hline Protestant & $88(44.0)$ & $70(35.0)$ & \multirow{4}{*}{48.1} & \multirow[t]{4}{*}{$<0.001$} \\
\hline Others (borne again) & $53(26.5)$ & $20(10.0)$ & & \\
\hline Catholic & $50(25.0)$ & $67(33.0)$ & & \\
\hline Seventh Day Adventist & $9(4.5)$ & $43(21.5)$ & & \\
\hline \multicolumn{5}{|l|}{ Education level } \\
\hline None & $11(5.5)$ & $149(74.5)$ & \multirow[t]{4}{*}{13.8} & \multirow[t]{4}{*}{0.030} \\
\hline Primary & $142(71.0)$ & $19(9.5)$ & & \\
\hline Secondary & $40(20.0)$ & $26(13.0)$ & & \\
\hline Tertiary & $7(3.5)$ & $6(3.0)$ & & \\
\hline \multicolumn{5}{|l|}{ Occupation } \\
\hline Peasant & $171(85.0)$ & $177(88.5)$ & \multirow[t]{3}{*}{3.6} & \multirow[t]{3}{*}{0.465} \\
\hline Salaried worker & $21(10.5)$ & $13(6.5)$ & & \\
\hline Others & $8(4.0)$ & $10(5.0)$ & & \\
\hline \multicolumn{5}{|c|}{ Monthly income (Uganda Shillings) } \\
\hline$<50,000$ & $158(79.0)$ & $142(71.0)$ & \multirow[t]{2}{*}{10.2} & \multirow[t]{2}{*}{0.038} \\
\hline 50,000 and greater & $42(21.0)$ & $58(29.0)$ & & \\
\hline
\end{tabular}

of diarrhea were significantly lower in intervention subcounty than the non-CLTS intervention subcounty $(t=-4.6, P<0.001)$.

\section{DISCUSSION}

The study examined the potential effects of CLTS implementation on sanitation and hygiene status focusing on knowledge, latrine, and handwashing status, and prevalence of diarrhea in children younger than 5 years and ODF status. The study results indicated that CLTS was effective in improving knowledge levels of communities on sanitation and hygiene. Therefore, community's exposure to CLTS processes such as pre and post-triggering sessions and follow-up visits is very important in CLTS implementation as a

TABLE 2

Knowledge levels of hygiene and sanitation among households in the two subcounties

\begin{tabular}{|c|c|c|c|c|}
\hline$\overline{\text { Variable }}$ & CLTS intervention areas $N=200, n(\%)$ & Non-CLTS intervention areas $N=200, n(\%)$ & $\mathrm{x}^{2}$ & $P$-value \\
\hline \multicolumn{5}{|c|}{ Knowledgeable on critical times of handwashing } \\
\hline Yes & $186(93.0)$ & $165(82.5)$ & \multirow[t]{2}{*}{10.3} & \multirow[t]{2}{*}{0.001} \\
\hline No & $14(7.0)$ & $35(17.5)$ & & \\
\hline \multicolumn{5}{|c|}{ Knowledgeable on causes of diarrhea among children } \\
\hline Yes & $180(90.0)$ & $174(87.0)$ & \multirow[t]{2}{*}{0.9} & \multirow[t]{2}{*}{0.347} \\
\hline No & $20(10.0)$ & $26(13.0)$ & & \\
\hline \multicolumn{5}{|c|}{ Knowledgeable on prevention of diarrhea } \\
\hline Yes & $172(86.0)$ & $134(67.0)$ & \multirow[t]{2}{*}{20.1} & \multirow[t]{2}{*}{$<0.001$} \\
\hline No & $28(14.0)$ & $66(33.0)$ & & \\
\hline \multicolumn{5}{|c|}{ Appreciated the benefits of having a latrine and handwashing facility } \\
\hline Yes & $154(77.0)$ & $190(95.0)$ & \multirow[t]{2}{*}{26.9} & \multirow[t]{2}{*}{$<0.001$} \\
\hline No & $46(23.0)$ & $10(5.0)$ & & \\
\hline \multicolumn{5}{|c|}{ Knowledgeable on sanitation and hygiene (overall) } \\
\hline Yes & $129(64.5)$ & $108(54.0)$ & \multirow[t]{2}{*}{4.6} & \multirow[t]{2}{*}{0.033} \\
\hline No & $71(35.5)$ & $92(46.0)$ & & \\
\hline
\end{tabular}

CLTS = community-led total sanitation. Bold indicates statistically significant association. 
TABLE 3

Latrine and handwashing status in the two subcounties

\begin{tabular}{|c|c|c|c|c|}
\hline Variable & $\begin{array}{l}\text { CLTS intervention area } \\
(N=200), n(\%)\end{array}$ & $\begin{array}{l}\text { Non-CLTS intervention area } \\
(N=200), n(\%)\end{array}$ & $x^{2}$ & $P$-value \\
\hline \multicolumn{5}{|c|}{ Has latrine } \\
\hline Yes & $195(97.5)$ & $183(91.5)$ & 6.9 & 0.100 \\
\hline \multicolumn{5}{|c|}{ Types of latrine } \\
\hline Pit & $190(97.4)$ & 177 (96.7) & 1.1 & 0.586 \\
\hline Others & $5(2.6)$ & $6(3.3)$ & & \\
\hline \multicolumn{5}{|c|}{ Latrine has a door } \\
\hline Yes & $100(51.3)$ & 45 (24.6) & 28.4 & $<0.001$ \\
\hline \multicolumn{5}{|c|}{ Latrine has screen walls } \\
\hline Yes & $158(81.0)$ & $150(82.0)$ & 0.06 & 0.814 \\
\hline \multicolumn{5}{|c|}{ Latrine has a roof } \\
\hline Yes & $178(91.3)$ & $131(71.6)$ & 24.5 & $<0.001$ \\
\hline \multicolumn{5}{|c|}{ Latrine has cover } \\
\hline Yes & $138(70.8)$ & $19(10.4)$ & 141.8 & $<0.001$ \\
\hline \multicolumn{5}{|c|}{ Presence of anal cleansing materials } \\
\hline Yes & $53(27.2)$ & $32(17.5)$ & 5.1 & 0.024 \\
\hline \multicolumn{5}{|c|}{ Latrine cleanliness } \\
\hline Good & 100 (51.3) & $25(13.7)$ & 72.8 & $<0.001$ \\
\hline Fair & 85 (43.6) & $110(60.1)$ & & \\
\hline Poor & $10(5.1)$ & 48 (26.2) & & \\
\hline \multicolumn{5}{|c|}{ Latrine quality } \\
\hline Good & $30(15.4)$ & $19(10.4)$ & 38.5 & $<0.001$ \\
\hline Fair & 143 (73.3) & 93 (50.8) & & \\
\hline Poor & $22(11.4)$ & $71(38.8)$ & & \\
\hline \multicolumn{5}{|c|}{ Has a handwashing facility } \\
\hline Yes & $144(72.0)$ & $58(29.0)$ & 74.0 & $<0.001$ \\
\hline \multicolumn{5}{|c|}{ Has a handwashing facility with water } \\
\hline Yes & $129(64.5)$ & $51(25.5)$ & 61.5 & $<0.001$ \\
\hline \multicolumn{5}{|c|}{ Handwashing after using a latrine } \\
\hline Yes & 177 (88.5) & $163(81.5)$ & 3.8 & 0.05 \\
\hline No & $23(11.5)$ & 37 (18.5) & & \\
\hline No & $23(11.5)$ & 37 (18.5) & & \\
\hline
\end{tabular}

way to increase their knowledge levels on sanitation and hygiene. Individuals who have adequate knowledge on sanitation and hygiene are more likely to adopt better sanitation and hygiene practices as this determines the individual attitudes to adopt positive behavior change as found in rural Zambia. ${ }^{7}$
Similarly, the proportion of households that achieved ODF status had good-quality latrines and possessed handwashing facilities with water and soap, for example, ash was higher in the CLTS intervention area than non-CLTS households. This may be attributed to the fact that CLTS helps to create

TABLE 4

ODF indicators and status between CLTS and non-CLTS intervention subcounties

\begin{tabular}{|c|c|c|c|c|}
\hline Variable & $\begin{array}{l}\text { CLTS intervention area } \\
(N=200), n(\%)\end{array}$ & $\begin{array}{l}\text { Non-CLTS intervention } \\
\text { area }(N=200), n(\%)\end{array}$ & $x^{2}$ & $P$-value \\
\hline \multicolumn{5}{|l|}{ ODF indicators } \\
\hline $\begin{array}{l}\text { 1. A functional latrine with a } \\
\text { superstructure and has a squat hole } \\
\text { with a tight-fitting cover or water seal }\end{array}$ & & & 141.8 & $<0.001$ \\
\hline Yes & $139(69.5)$ & $19(9.5)$ & & \\
\hline No & $61(30.5)$ & $181(90.5)$ & & \\
\hline $\begin{array}{l}\text { 2. Presence of a handwashing facility with } \\
\text { water and soap or soap substitute near } \\
\text { a latrine }\end{array}$ & & & 52.0 & $<0.001$ \\
\hline Yes & $111(55.5)$ & $41(20.5)$ & & \\
\hline No & $89(44.5)$ & 159 (79.5) & & \\
\hline 3. No feces seen around the vicinity & & & 0.4 & 0.506 \\
\hline Yes & $140(70.0)$ & $146(73.0)$ & & \\
\hline No & $60(30.0)$ & 54 (27.0) & & \\
\hline \multicolumn{5}{|l|}{$\begin{array}{l}\text { 4. Evidence of latrine use and } \\
\text { handwashing with soap or soap } \\
\text { substitute after visiting the latrine }\end{array}$} \\
\hline Yes & $117(58.5)$ & 63 (31.5) & - & - \\
\hline No & $83(41.5)$ & $137(68.5)$ & 29.5 & $<0.001$ \\
\hline \multicolumn{5}{|l|}{ Overall ODF status } \\
\hline Yes & 70 (35.0) & $12(6.0)$ & 51.6 & $<0.001$ \\
\hline No & $130(65.0)$ & $188(94.0)$ & & \\
\hline
\end{tabular}


TABLE 5

Bivariate and multivariate analyses of factors associated with ODF status

\begin{tabular}{|c|c|c|c|c|c|c|}
\hline \multirow[b]{2}{*}{ Variable } & \multicolumn{2}{|c|}{ ODF status } & \multirow[b]{2}{*}{$\operatorname{COR}(95 \% \mathrm{Cl})$} & \multirow[b]{2}{*}{$P$-value } & \multirow[b]{2}{*}{ AOR $(95 \% \mathrm{Cl})$} & \multirow[b]{2}{*}{$P$-value } \\
\hline & No $(n=318), n(\%)$ & Yes $(n=82), n(\%)$ & & & & \\
\hline \multicolumn{7}{|l|}{ Gender } \\
\hline Male & 254 (79.9) & $72(87.8)$ & 1.0 & - & - & - \\
\hline Female & $64(20.1)$ & 10 (12.2) & $0.55(0.27-1.12)$ & 0.103 & $1.03(0.37-2.96)$ & 0.941 \\
\hline \multicolumn{7}{|l|}{ Age (years) } \\
\hline $18-35$ & $84(26.4)$ & $24(29.3)$ & 1.0 & - & - & - \\
\hline $36-55$ & $118(37.1)$ & $37(45.1)$ & $1.10(0.61-1.96)$ & 0.755 & $1.32(0.70-2.50)$ & 0.390 \\
\hline 56 and older & 116 (36.5) & $21(25.6)$ & $0.63(0.33-1.21)$ & 0.169 & $1.37(0.64-2.92)$ & 0.420 \\
\hline \multicolumn{7}{|l|}{ Household number } \\
\hline $1-5$ & $100(31.5)$ & $20(24.4)$ & 1.0 & - & - & - \\
\hline $6-10$ & $139(43.7)$ & $41(50.0)$ & $1.47(0.81-2.67)$ & 0.199 & - & - \\
\hline 11 and above & $79(24.8)$ & $21(25.6)$ & $1.33(0.67-2.62)$ & 0.412 & - & - \\
\hline \multicolumn{7}{|l|}{ Marital status } \\
\hline Not married & $35(11.0)$ & $8(9.8)$ & 1.0 & - & - & - \\
\hline Married & $283(89.0)$ & $74(90.2)$ & $1.14(0.51-2.57)$ & 0.745 & $0.45(0.14-1.48)$ & 0.190 \\
\hline \multicolumn{7}{|l|}{ Education level } \\
\hline Primary and below & $268(84.3)$ & $60(73.2)$ & - & - & - & - \\
\hline Postprimary & $50(15.7)$ & $22(26.8)$ & $1.97(1.11-3.49)$ & 0.021 & $1.47(0.76-2.84)$ & 0.254 \\
\hline \multicolumn{7}{|l|}{ Occupation } \\
\hline Farmer & $280(88.1)$ & $68(82.9)$ & 1.0 & - & - & - \\
\hline Others & $38(11.9)$ & $14(17.1)$ & $1.52(0.78-2.96)$ & 0.221 & $1.38(0.63-3.01)$ & 0.418 \\
\hline \multicolumn{7}{|l|}{ Monthly income } \\
\hline$<50,0000$ & $243(76.4)$ & 57 (69.5) & 1.0 & - & - & - \\
\hline Greater than 50,000 & $75(23.6)$ & $25(30.5)$ & $1.42(0.83-2.43)$ & 0.199 & - & - \\
\hline \multicolumn{7}{|c|}{ Knowledgeable on sanitation and hygiene } \\
\hline Yes & $142(44.7)$ & $61(74.4)$ & 1.0 & - & - & - \\
\hline No & $176(55.4)$ & $21(25.6)$ & $2.34(1.36-4.03)$ & 0.002 & $2.23(1.24-4.03)$ & 0.008 \\
\hline \multicolumn{7}{|l|}{ CLTS status } \\
\hline Non-CLTS intervention area & $188(94.0)$ & $12(6.0)$ & 1.0 & - & - & - \\
\hline CLTS intervention area & $130(65.0)$ & $70(35.0)$ & $8.44(4.40-16.19)$ & $<0.001$ & $8.89(4.26-18.56)$ & $<0.001$ \\
\hline \multicolumn{7}{|c|}{ Presence of child younger than 5 years with diarrhea } \\
\hline Yes & $131(41.2)$ & $18(21.9)$ & 1.0 & - & - & - \\
\hline No & $187(58.8)$ & $64(78.1)$ & $2.49(1.41-4.40)$ & 0.002 & $1.51(0.80-2.56)$ & 0.206 \\
\hline
\end{tabular}

demand for safe sanitation and hygiene through the CLTS triggering processes, which ignite individuals and families to build and use latrines and handwashing facilities. These findings are largely comparable to previous studies conducted in low- and middle-income countries including Ethiopia, ${ }^{9}$ Kenya, ${ }^{8}$ Niger, ${ }^{13}$ and Uganda. ${ }^{15}$

It is further important to note that most latrines observed in both study areas in Pallisa district were traditional pit latrines mainly made of local materials. Use of local materials/ solutions to construct latrines by households in the intervention area is consistent with findings from Ghana ${ }^{16}$ and reinforces some of the key pillars of CLTS of ensuring local solutions and cooperation that increase the uptake of sanitation facilities. However, as previously noted, the use of local materials for construction of latrines sometimes results in poor-quality latrines, a key limitation of the CLTS approach. ${ }^{17,18}$ Indeed, despite good latrine coverage in both the intervention and nonintervention areas, most latrines did not have tight-fitting squat-hole covers. The significant proportion of latrines without tight-fitting squat-hole covers indicated that the fecal-oral route of disease transmission was not completely interrupted, and people could have continued to be exposed to excreta through food/fluids contaminated by flies, exposing them to fecal-oral diseases. Findings in relation to latrines having squat holes with/without tight-fitting covers were consistent with those from studies conducted by WaterAid and UNICEF. ${ }^{19}$
Achieving ODF status was associated with CLTS implementation in multivariate analysis. The findings support the argument that participatory sanitation approaches such as CLTS trigger communities to demand for sanitation and hygiene facilities and adopt sustained behavior change leading to abandonment of open defecation practices. ${ }^{2,20}$ In relation to other factors influencing ODF status, knowledge of sanitation and hygiene is important because it influences the individual's attitudes to adopt sustained behavioral change. This stimulates demand for sanitation and hygiene facilities without external subsidies or support in construction of facilities. ${ }^{5}$ It is thus important that when implementing CLTS in the community, priority is given to equipping communities with sufficient knowledge about sanitation and hygiene. Moreover, beyond CLTS, behavior change communication interventions should be considered for their importance in supporting behavior adoption. In bivariate analysis, post-primary education was associated with achievement of ODF status in nonCLTS intervention subcounty. However, the association disappeared in the multivariate analysis, indicating that education level was not a standalone factor that can be linked to achievement of ODF communities. Thus, irrespective of individual's education level in households, ODF status can be achieved as long as quality triggering and follow-up of triggered communities are performed to equip communities with knowledge about hygiene and sanitation, one of the predictors for ODF status in communities. 
The difference in availability of handwashing facilities with water and soap, evidence of use of handwashing facility, latrine coverage, and knowledge on sanitation and hygiene might explain the difference in diarrhea cases between the intervention and nonintervention subcounties. This supports the argument that CLTS intervention significantly contributes to the reduction in diarrheal morbidities in communities, and it demonstrates that there is adoption of sustained positive behavior change by individuals and communities. ${ }^{9}$ However, attributing CLTS interventions to reduction in sanitation-related diseases is difficult because it is virtually impossible to isolate the effects of other interventions. The findings from this study are in line with the study conducted in Nyando district, Kenya, which established that there were significant differences in disease cases between CLTS and non-CLTS households for diarrhea. ${ }^{8}$

Study limitations and strengths. This study provides information regarding associations between CLTS implementation and health outcomes over a long implementation period of 6 years unlike most previous studies that usually had a short duration and/or assessed only short-term outcomes. We recognize that the study's cross-sectional design provides associations which are not indicative of causality. The study used quantitative research techniques involving semi-structured questionnaires and observational checklists, which provided reliable information. However, response biases may have affected the reliability and quality of the results as the respondents, especially in the intervention areas, may have been prone to providing socially desirable responses. Although we controlled for potential confounders in multivariate analysis, the other analysis techniques did not do so, and their findings should be interpreted in light of this. Moreover, even though the CLTS intervention did not take place in the nonintervention subcounty, we cannot rule out the possibility of other interventions such as health education in schools, and health facilities or mass media could have impacted our outcomes. However, this could only have worked to reduce the strength of the CLTS intervention during comparison of the study outcomes between subcounties.

Conclusion. Respondents in the CLTS intervention area had higher knowledge of sanitation and hygiene than those in the non-CLTS area. The proportion of households that achieved the ODF status was higher in CLTS intervention subcounty than in the non-CLTS intervention subcounty. The prevalence of diarrhea was lower in the intervention area than in the nonintervention area. Although this evidence is from a cross-sectional study, scaling up CLTS to all subcounties and equipping communities with knowledge on sanitation and hygiene could reduce ODF and the burden of diarrheal diseases in communities.

Received December 7, 2019. Accepted for publication July 17, 2020.

Published online August 17, 2020.

Note: Supplemental information appears at www.ajtmh.org.

Acknowledgments: We thank the study participants for participating in the study and the Pallisa district local government for its support. The American Society of Tropical Medicine and Hygiene (ASTMH) assisted with publication expenses.

Authors' addresses: Charles Dickens Okolimong, Department of Disease Control and Environmental Health, School of Public Health, College of Health Sciences, Makerere University, Kampala, Uganda, and Pallisa District Local Government, Pallisa, Uganda, E-mail: c.okolimong@yahoo.com. Rawlance Ndejjo, Richard K. Mugambe, and Abdullah Ali Halage, Department of Disease Control and Environmental Health, School of Public Health, College of Health Sciences, Makerere University, Kampala, Uganda, E-mails: rndejo@musph.ac.ug, rkmugambe@musph.ac.ug, and ahalage@musph.ac.ug.

\section{REFERENCES}

1. WHO, 2019. Progress on Household Drinking Water, Sanitation and Hygiene 2000-2017: Special Focus on Inequalities. Geneva, Switzerland: World Health Organization.

2. Institute of Development studies, 2015. Community Led Total Sanitation in Uganda. Available at: http://www.communityledtotalsanitation. org/country/Uganda. Accessed October 10, 2019.

3. $\mathrm{MOH}, 2014$. Annual Health Sector Performance Report. Available at: https://www.ucmb.co.ug/files/UCMBdocs/Reports/ARTICLES/ Final\%20AHSPR\%202013_2014.pdf. Accessed October 13, 2019.

4. Water Aid, 2011. Uganda Annual Report-Water Sanitation and Hygiene. Available at: www.wateraid.org/water-aid-ugandaannualreport-2011-2012.pdf. Accessed October 13, 2019.

5. Kar K, Chambers R, 2008. Handbook on Community-Led Total Sanitation. Brighton, UK: Institute of Development Studies at the University of Sussex.

6. IRSP, 2014. CLTS Implementation, Process and Impact. Available at: www.irsp.org.pk. Accessed May 22, 2019.

7. Lawrence JJ, Yeboah-Antwi K, Biemba G, Ram PK, Osbert N, Sabin LL, Hamer DH, 2016. Beliefs, behaviors, and perceptions of community-led total sanitation and their relation to improved sanitation in rural Zambia. Am J Trop Med Hyg 94: 553-562.

8. Makotsi N, Kaseje D, Mumma J, Opiyo J, Lukorito L, 2013. Association of community led total sanitation to reduced household morbidity in Nyando district. IJSBAR 28: 220-230.

9. Eshete N, Beyene A, Terefe G, 2015. Implementation of community-led total sanitation and hygiene approach on the prevention of diarrheal disease in Kersa district, Jimma zone Ethiopia. Sci J Public Health 3: 669-676.

10. UBOS, 2016. The National Population and Housing Census 2014 Main Report. Available at: http://www.ubos.org/onlinefiles/uploads/ ubos/NPHC/NPHC\%202014\%20FINAL\%20RESULTS\% 20REPORT.pdf. Accessed May 22, 2019.

11. DHIS2, 2017. District Health Management Information System. Pallisa District Sanitation and Hygiene Annual Report. Pallisa, Uganda: District Health Office.

12. Schlesselman JJ, 1982. Case-Control Studies: Design, Conduct, Analysis. Oxford, UK: Oxford University Press.

13. Tyndale-Biscoe P, Bond M, Kidd R, 2013. Plan International ODF Sustainability Study. Available at: http://www.communityledtotals anitation.org/sites/communityledtotalsanitation.org/files/Plan International_ODF_Sustainability_Study.pdf. Accessed March 15, 2019.

14. World Health Organization, 2019. Diarrhoea. Geneva, Switzerland: WHO. Available at: https://www.who.int/topics/diarrhoea/en/. Accessed November 11, 2019.

15. Vidya V, Alexandra S, 2015. Testing CLTS Approaches for Scalability (TCAS) Project. Available at: waterinstitute.unc.edu/clts. Accessed March 15, 2019.

16. Magala JM, Roberts L, 2009. Evaluation of Strategy for Scaling up Community-Led Total Sanitation in Ghana. Accra, Ghana: UNICEF. Available at: https://www.communityledtotalsanitation.org/resource/ evaluation-strategy-scaling-clts-ghana. Accessed November 7, 2014.

17. Thomas $A, 2016$. Strengthening post-ODF programming: reviewing lessons from sub-Saharan Africa. Sustainable Sanitation for All: Experiences, Challenges, and Innovations. Warwickshire, UK: Practical Action Publishing Ltd., 83.

18. Venkataramanan V, Crocker J, Karon A, Bartram J, 2018. Communityled total sanitation: a mixed-methods systematic review of evidence and its quality. Environ Health Perspectives 126: 026001.

19. Water Aid, UNICEF, 2016. Second Review of Community Led Total Sanitation in the East and Pacific Region, East Asia and Pacific Region. New York, NY: UNICEF.

20. Alzua ML, Pickering AJ, Djebbari H, Lopez C, Cardenas JC, Lopera MA, Osbert N, Coulibaly M, 2015. Impact Evaluation of Community-Led Total Sanitation (CLTS) In Rural Mali: Documento de Trabajo. Hamburg, Germany: Leibniz Information Centre for Economics. 